\title{
Microvascular obstruction assessed by 3-tesla magnetic resonance imaging in acute myocardial infarction is correlated with plasma troponin I levels
}

\author{
Karine Pernet, Fiona Ecarnot, Romain Chopard, Marie-France Seronde, Philoktimon Plastaras, Francois Schiele \\ and Nicolas Meneveau*
}

\begin{abstract}
Background: Microvascular obstruction (MVO) at the acute phase of myocardial infarction (MI) is associated with poor prognosis. We aimed to evaluate the correlation between plasma cardiac troponin I (cTnl) at the acute phase of $\mathrm{Ml}$ and extent of no-reflow, as assessed by 3-T cardiac magnetic resonance imaging (MRI). Secondly, we defined a cut-off value for cTnl predictive of no-reflow.

Methods: 51 consecutive patients with no previous history of cardiovascular disease, presenting ST elevation Ml within $<12 \mathrm{~h}$. Infarct size and extent of no-reflow were evaluated by 3-T MRI at day 5. Extent of no-reflow at 15 minutes (MVO) was correlated with cTnl at admission, 6, 12, 24, 48 and 72 hours. At 6 months, MRI was performed to evaluate the impact of MVO on LV remodeling.

Results: MVO was diagnosed in 29 patients (57\%). Extent of MVO was significantly correlated to peak troponin, cTnl (except admission values) and area under the curve. Using Receiver-operating characteristic (ROC) curve analysis, a cut-off cTnl value $>89 \mathrm{ng} / \mathrm{mL}$ at $12 \mathrm{~h}$ seemed to best predict presence of early MVO (sensitivity $63 \%$, specificity 88\%). At 6 months, MVO was associated with left ventricular (LV) remodeling, resulting in higher LV volumes.

Conclusion: There is a relationship between CTnl at the acute phase of AMI and extent of MVO as assessed by 3-T cardiac MRI. A cut-off cTnl value of $89 \mathrm{ng} / \mathrm{mL}$ at $12 \mathrm{~h}$ seems to best predict presence of MVO, which contributes to LV remodeling.
\end{abstract}

Keywords: Myocardial infarction, MRI, Troponin, Microvascular obstruction

\section{Background}

In acute ST-segment-elevation myocardial infarction (STEMI), primary percutaneous coronary intervention is the treatment of choice to restore myocardial revascularization and minimize ischemic damage to the myocardium [1]. Several studies have demonstrated that microvascular dysfunction after infarct-related artery revascularization is associated with myocardial reperfusion injury, resulting in greater infarct size [2-10], left ventricular impairment [3-5,7,11-17], recurrent MI [2-4,14], heart failure $[2-4,12,14]$ and higher mortality $[2-5,12,14,18,19]$.

\footnotetext{
* Correspondence: nicolas.meneveau@univ-fcomte.fr Department of Cardiology, EA3920, University Hospital Jean Minjoz, Boulevard Fleming, Besançon 25000, France
}

In addition, microvascular dysfunction has a negative prognostic value, irrespective of infarct size [3]. Magnetic Resonance Imaging (MRI) is not systematically performed in routine practice, and it would thus be useful if there was a more accessible prognostic marker that could identify patients with microvascular obstruction (MVO). Cardiac troponin levels correlate well with infarct size [20] and are of prognostic value in the short and long term [21].

The aim of our study was to evaluate the relationship between plasma levels of cardiac troponin I (cTnI) and microvascular obstruction (MVO) as assessed by magnetic resonance imaging (MRI) at day 5 , and to define a cut-off value for cTnI that predicts MVO. 


\section{Methods}

\section{Study population}

This study was a prospective single-center study. Patients $<75$ years old referred to our department for a first ST elevation MI (STEMI) and admitted within 12 hours of symptom onset were considered for inclusion. MI was defined by the guidelines of the joint Task Force of the European Society of Cardiology (ESC), the American College of Cardiology (ACC), the American Heart Association (AHA), and the World Heart Federation (WHF) [1,22]. MI was confirmed by detection of elevated cardiac biomarkers (at least one value above the $99^{\text {th }}$ percentile of the upper reference limit (URL)), together with evidence of myocardial ischemia (i.e., new ST-T changes or new left bundle branch block, or development of pathological Q waves in the ECG).

Exclusion criteria were: previous cardiovascular or pulmonary diseases, cardiogenic shock and contraindication for MRI.

The study protocol was approved by the local ethics committee (Comité de Protection des Personnes Est II, University Hospital Besancon, France) and informed consent was obtained from all enrolled patients.

\section{Angiographic evaluation}

All patients were referred to the catheterization laboratory within the first 24 hours after admission for coronary angiogram, and received medication according to current guidelines [1].

The initial and post-procedural blood flow in the infarct-related artery was graded according to the Thrombolysis in Myocardial Infarction (TIMI) grading system [23]. A successful procedure was defined by a TIMI flow grade $=3$ and residual stenosis $<20 \%$.

\section{Magnetic resonance imaging}

All CE-MRI studies were conducted at 3.0 field strength (Signa HD, General Electric Healthcare, Milwaukee, WI, USA) and performed in the acute phase and repeated at 6 months. Left ventricular function was assessed by ECG-gated cine steady-state free precession (SSFP) breathhold sequences in the two-chamber and four-chamber views as well as in the short cardiac axis from base to apex (30 phases per cardiac cycle; repetition time $3.5 \mathrm{~ms}$, echo time $1.2 \mathrm{~ms}$, flip angle $45^{\circ}$, typical voxel size $1.92 \times 1.25 \times$ $8.0 \mathrm{~mm})$.

Contrast-enhancement imaging was performed at 3 and 15 min with a breath-hold ECG-gated T1-weighted sequence after the injection of a bolus of gadolinium (Dota-Gd; Guerbet, Roissy, France) at a single dose of $0.1 \mathrm{mmol} / \mathrm{kg}$ (TE = MinFull/field of view $440 \mathrm{~mm} / \mathrm{TI}=$ optimised to obtain an optimal myocardial nulling/matrix $256 \times 224$, interpolated $256 \times 256 /$ slice thickness $=$
$8 \mathrm{~mm} / \mathrm{gap}=1 \mathrm{~mm})$. The number and position of slices were the same as used for functional imaging.

Image analysis was performed in a blind fashion by two operators using an off-line dedicated workstation (General Electric Healthcare, Milwaukee, WI, USA). Left ventricular (LV) ejection fraction (LVEF), end-diastolic (LVEDVI) and end-systolic volume index (LVESVI) and mass were calculated from SSFP short-axis views. MVO was assessed on the initial CE-MRI performed during inhospital stay. Infarct size was assessed from the same initial CE-MRI and at 6 months follow-up. Infarct size and MVO (if present) were manually traced from the contrastenhancement short-axis images [24]. Myocardial regions was considered infarcted if the infarct size signal intensity was $>2$ SDs above the remote myocardium. MVO was defined as a dark zone within the infarcted segments, usually located in the subendocardium. MVO and infarct size are expressed as a percentage of LV mass assuming $1.05 \mathrm{~g} / \mathrm{ml}$ as the specific gravity of myocardium.

\section{Enzyme measurement}

Serum levels of troponin I (TnI), creatine kinase (CK) and creatine kinase isoenzyme myocardial and brain (CK-MB) were determined on admission, and 6, 12, 24, and 48 hours after onset of MI. cTnI was measured quantitatively using sandwich immunoassay (Dimension RXL max, SIEMENS, Germany). The lower limit of detection for this assay was $0.04 \mathrm{ng} / \mathrm{ml}$. A value of cTnl $>0.15 \mathrm{ng} / \mathrm{ml}$ was considered indicative of myocardial necrosis for the purposes of clinical care. The peak level was determined as the highest value.

\section{Statistical analysis}

Quantitative continuous variables are expressed as mean \pm standard deviation, and qualitative variables as number and percent. The Student t test and Chi square or Fisher's exact tests were used for comparisons, as appropriate. We calculated the relative change at 6 months from baseline in LV end-diastolic volume index, LV end-systolic volume index, and LV ejection fraction. The model used to take initial infarct size into account was the calculation of relative change, normalized for baseline infarct size. The correlations between serum enzyme levels and MVO at day 5 were assessed using the Spearman rank test. A receiveroperating characteristic (ROC) curve was used to define the threshold value of troponin levels predictive of MVO at day 5. A p-value $<0.05$ was considered statistically significant. All analyses were performed using SAS version 9.2 (SAS Institute, Cary, NC, USA).

\section{Results}

\section{Patient characteristics}

Between 2006 and 2008, 51 patients were enrolled in the study. Mean age was 54 years; there were 9 women and 
42 men. Baseline and angiographic characteristics of the study population are shown in Table 1. Eighteen patients (35\%) had anterior MI location. All patients underwent coronary angiogram and angioplasty within the first 24 hours. Reperfusion therapy was initiated $5.3 \pm 3.2$ hours after the onset of symptoms, by primary PCI in 37 patients (73\%) and thrombolysis in 14 patients (27\%). In patients who underwent thrombolysis, rescue PCI was performed in 6 patients (12\%) and the remaining 8 underwent systematic PCI within the first 24 hours after reperfusion.

Twenty-nine patients (57\%) had MVO (MVO ${ }^{\text {pos }}$ patients) diagnosed by MRI and 22 (43\%) had no MVO $\left(\mathrm{MVO}^{\text {neg }}\right.$ patients). $\mathrm{MVO}^{\mathrm{pos}}$ and $\mathrm{MVO}^{\text {neg }}$ patients were comparable as regards baseline characteristics. The percentage of patients with TIMI flow grade $\leq 2$ before PCI was significantly higher in the $\mathrm{MVO}{ }^{\text {pos }}$ group. After $\mathrm{PCI}$, the rate of TIMI flow grade 3 was comparable in both groups (Figure 1).

During follow-up, there were 0 deaths, and 4 revascularisations (1 for recurrent MI due to stent thrombosis at 12 days and 3 on arteries other than the infarctrelated artery).

\section{Magnetic resonance imaging}

MRI was performed at $5.7 \pm 2.7$ days after symptom onset and at $6 \pm 1$ months follow-up. MRI was not performed in 6 patients at 6 months due to patient refusal, or intervention (PCI or $\mathrm{CABG}$ ) during the follow-up period.

At day 5, the extent of MVO was $7.3 \pm 3.7 \%$. Infarct size was $23.5 \pm 8.4 \%$ in $\mathrm{MVO}^{\text {pos }}$ patients versus $12.7 \pm$ 9.4\% in $\mathrm{MVO}^{\text {neg }}$ patients $(\mathrm{p}=0.0001)$. There was a significant correlation between the extent of MVO at day 5 and the infarct size at day $5(\mathrm{r}=0.61, \mathrm{p}<0.0001)$. Similarly, we observed a significant correlation between extent of MVO and time to reperfusion $(r=0.43, p=0.004)$.

At 6 months follow-up, a significant positive correlation was observed among $\mathrm{MVO}^{\text {pos }}$ patients between MVO at day 5 and infarct size at 6 months (Figure 2). In $\mathrm{MVO}^{\text {pos }}$ patients, the relative change in LV end-diastolic volume index (LVEDVI) and in LV end-systolic volume

Table 1 Baseline and angiographic characteristics

\begin{tabular}{|c|c|c|c|c|}
\hline & $\begin{array}{l}\text { All patients } \\
\quad \mathrm{N}=51\end{array}$ & $\begin{array}{l}\text { Pts MVO }{ }^{\text {neg }} \\
\mathrm{N}=22(43 \%)\end{array}$ & $\begin{array}{l}\text { Pts } \mathrm{MVO}^{\text {pos }} \\
\mathrm{N}=29(57 \%)\end{array}$ & $P$ \\
\hline Age - years & $53.6 \pm 9.9$ & $56 \pm 10$ & $52.6 \pm 9.4$ & 0.27 \\
\hline Female (\%) & $9(18)$ & $4(19)$ & $5(17.5)$ & 0.93 \\
\hline Arterial hypertension (\%) & $18(35)$ & $7(32)$ & $11(38)$ & 0.65 \\
\hline Diabetes mellitus (\%) & $11(22)$ & $5(23)$ & $6(21)$ & 0.86 \\
\hline Family history of CAD (\%) & $15(29)$ & $7(32)$ & $8(27)$ & 0.74 \\
\hline Current smoking & $42(82)$ & $18(82)$ & $24(83)$ & 0.93 \\
\hline Hyperlipidemia (\%) & $21(41)$ & $9(41)$ & $12(41)$ & 0.97 \\
\hline Body mass index $\geq 30 \mathrm{Kg} / \mathrm{m}^{2}(\%)$ & $9(18)$ & $3(14)$ & $6(20.6)$ & 0.51 \\
\hline One vessel disease (\%) & $28(55)$ & $13(59)$ & $15(52)$ & 0.60 \\
\hline Multivessel disease (\%) & $16(31)$ & $7(32)$ & $9(31)$ & 0.95 \\
\hline Stenosis $<50 \%(\%)$ & $7(14)$ & $2(9)$ & $5(17)$ & 0.40 \\
\hline Anterior location (\%) & $18(35)$ & $9(41)$ & $9(31)$ & 0.46 \\
\hline Time from symptom onset to $1^{\text {st }}$ reperfusion therapy - hours & $5.3 \pm 3.2$ & $4.7 \pm 2.9$ & $5.9 \pm 3.7$ & 0.21 \\
\hline Fibrinolysis (\%) & $14(27)$ & $5(23)$ & $9(31)$ & 0.73 \\
\hline Primary PCI (\%) & $37(73)$ & $17(77)$ & $20(69)$ & \\
\hline Rescue PCI (\%) & $6(12)$ & $2(9)$ & $4(14)$ & 0.94 \\
\hline Aspirin & $51(100)$ & $22(100)$ & $29(100)$ & 1 \\
\hline Clopidogrel loading dose $(300 / 600 \mathrm{mg})$ & $34 / 17$ & $14 / 8$ & $20 / 9$ & 0.69 \\
\hline GP Ilb-Illa inhibitors (\%) & $22(43)$ & $8(36)$ & 14(48) & 0.39 \\
\hline Tnl peak (ng/mL) (range) & $81 \pm 71$ & $53.6(13-225)$ & $118.5(22-585)$ & 0.0006 \\
\hline CK peak, U/L (range) & $1985 \pm 1522$ & $1825(63-9580)$ & $2663(160-9930)$ & 0.006 \\
\hline CK-MB peak, U/L (range) & $124 \pm 132$ & 145.6 (9-940) & $189.1(9-760)$ & 0.09 \\
\hline
\end{tabular}

Pts $\mathrm{MVO}^{\text {neg }}=$ patients without microvascular obstruction; Pts $\mathrm{MVO}^{\text {pos }}=$ patients with microvascular obstruction; $\mathrm{CAD}=$ coronary artery disease; $\mathrm{PCl}=$ percutaneous coronary intervention; $\mathrm{Tnl}=$ troponin I; $\mathrm{CK}=$ creatine kinase; $\mathrm{CK}-\mathrm{MB}=$ creatine kinase isoenzyme myocardial and brain. 


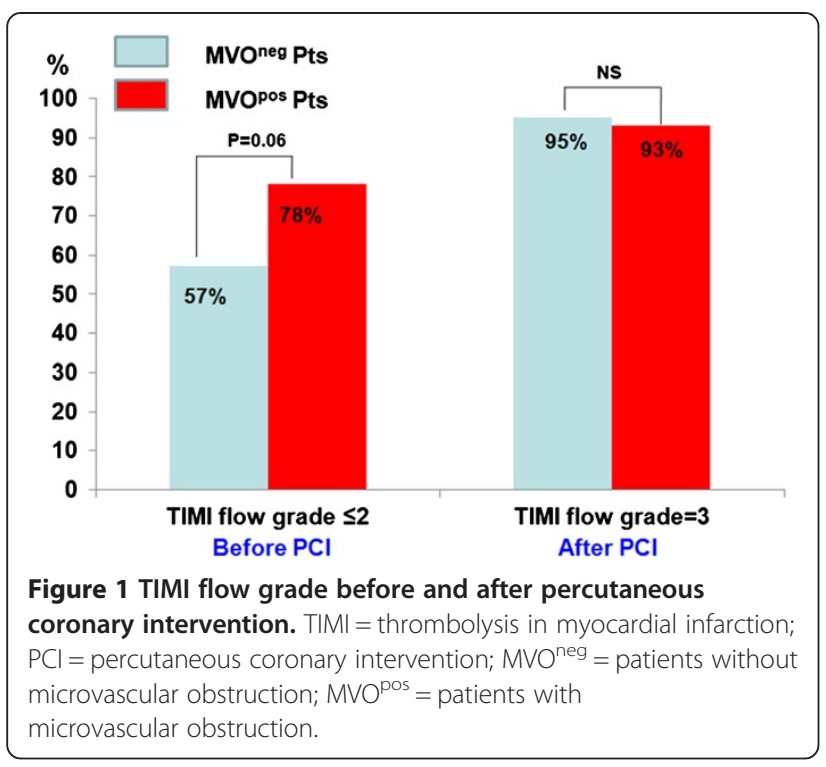

index (LVESVI) was significantly greater than in $\mathrm{MVO}^{\text {neg }}$ patients $(\mathrm{p}=0.002$ for LVEDVI, $\mathrm{p}=0.004$ for LVESVI) (Figure 3). There was no significant difference in relative change in LV ejection fraction (LVEF).

\section{Enzyme measurement}

Peak troponin and peak CK were significantly higher in $\mathrm{MVO}^{\text {pos }}$ patients (respectively $\mathrm{p}=0.0006$ and $\mathrm{p}=0.006$ ) (Table 1).

There was no significant difference in terms of peak troponin values between patients with TIMI flow grade 3 and those with TIMI flow $\leq 2$ after revascularisation (peak troponin $75 \pm 58$ vs $83 \pm 65$, TIMI 3 vs $\leq 2$ respectively, $\mathrm{p}=0.65$ ).

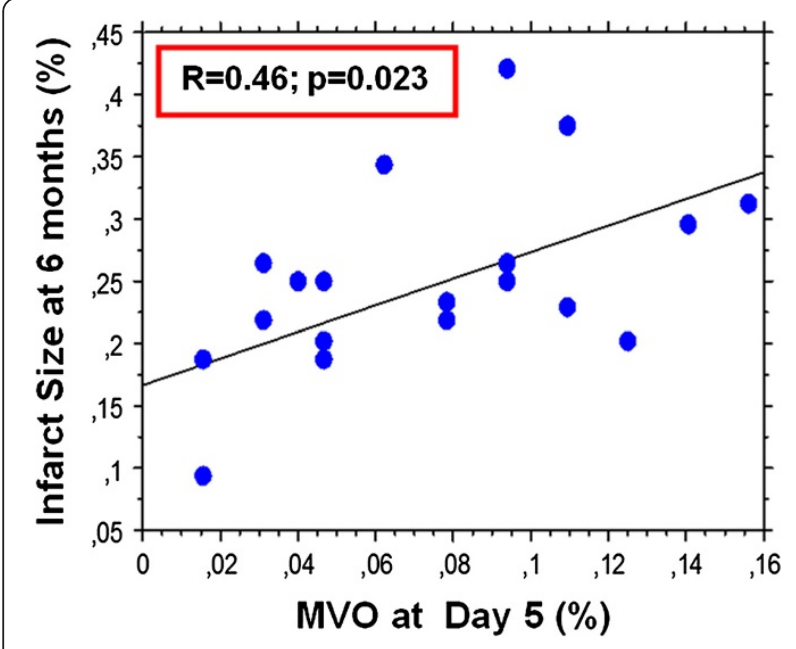

Figure 2 Relationship between MVO at Day 5 and infarct size at 6 months. $\mathrm{MVO}=$ microvascular obstruction; $\mathrm{MVO}^{\mathrm{pos}}=$ patients with microvascular obstruction.

\section{Correlation between the extent of MVO and troponin I levels}

The extent of MVO at day 5 was significantly correlated with peak troponin (Figure 4) and troponin I levels at 6 , 12, 24, 48 and 72 hours (Table 2). Infarct size was significantly correlated with peak troponin $(\mathrm{p}<0.0001)$ and the different $\mathrm{cTnI}$ levels $(\mathrm{p}<0.001)$, except $\mathrm{cTnI}$ at admission.

\section{Relationship between the presence of MVO and troponin I levels}

Peak troponin and all cTnI levels except cTnI at admission were significant predictors of MVO (Table 3). The Area under the curve (ROC) varied from 0.68 for tropo$\mathrm{nin}$ at $72 \mathrm{~h}$ to 0.766 for troponin at $12 \mathrm{~h}$. Sensitivity varied from $56 \%$ for troponin at $48 \mathrm{~h}$ to $74 \%$ for troponin at $6 \mathrm{~h}$. Specificity ranged from $65 \%$ for troponin at $6 \mathrm{~h}$ and $72 \mathrm{~h}$ to $88 \%$ for troponin at $12 \mathrm{~h}, 48 \mathrm{~h}$ and the AUC troponin. Using ROC curve analysis, a cTnI level $>89 \mathrm{ng} / \mathrm{ml}$ at 12 hours was found to be the best cut-off value to predict $\mathrm{MVO}$ with a sensitivity of $63 \%$ and a specificity of $88 \%(\mathrm{p}<0.0002)$ (Figure 5$)$.

\section{Discussion}

We aimed to find an accessible prognostic marker that could identify patients with microvascular dysfunction after reperfusion at the acute phase of myocardial infarction. Our data demonstrated that troponin levels (except troponin at admission), and particularly peak troponin, were correlated with the extent of MVO on MRI at day 5. A troponin I level $>89 \mathrm{ng} / \mathrm{ml}$ at 12 hours was found to be the best cut-off value to predict MVO, with a sensitivity of $63 \%$ and a specificity of $88 \%$.

The phenomenon of no-reflow $[25,26]$ or microvascular obstruction is due to microembolization of atherosclerotic debris or thrombotic material, intimal oedema, tissue haemorrhage and/or leukocyte sticking [8,27], and is diagnosed well by MRI $[3,6,13,28]$. In addition, besides microvascular obstruction, intra-myocardial hemorrhage and microvascular destruction have also been shown to play an important role in this setting [29]. At the acute phase of MI, the successful restoration of epicardial coronary artery patency does not always lead to adequate reperfusion at the microvascular level. In our study, although 93 to $95 \%$ of the patients had a TIMI flow grade $=3$ after PCI at $24 \mathrm{~h}$, MVO was diagnosed by MRI in $57 \%$ of cases at day 5 . There was no significant difference in peak troponin between patients with TIMI flow grade 3 and those with TIMI flow $\leq 2$ after revascularisation. Several studies have shown that microvascular dysfunction after infarct-related artery revascularization is associated with myocardial reperfusion injury, resulting in greater infarct size [2-10], left ventricular impairment [3-5,7,11-17], recurrent MI [2-4,14], heart failure $[2-4,12,14]$ and higher mortality $[2-5,12,14,18,19]$. In 

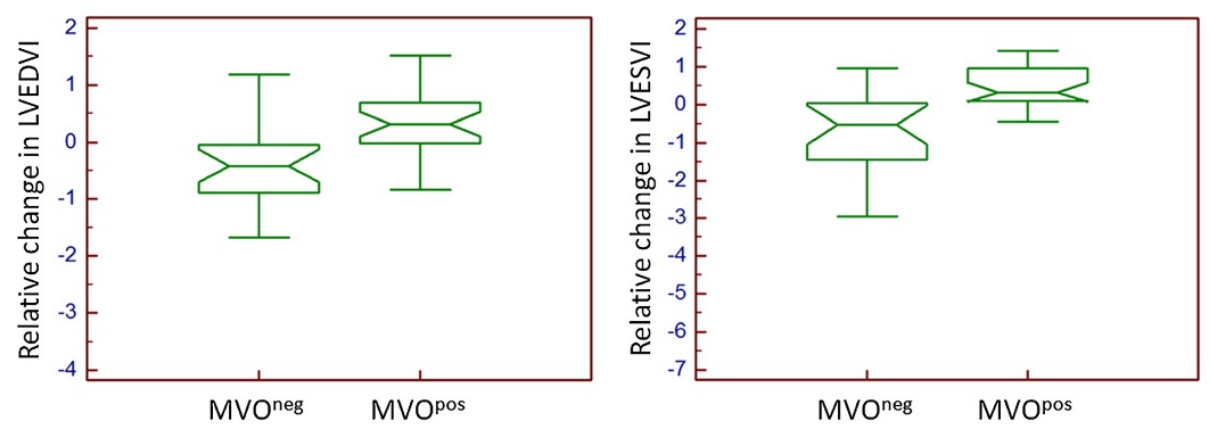

Figure 3 Relative change at 6 months from baseline in left ventricular end-diastolic volume index (LVEDVI) and left ventricular endsystolic volume index (LVESVI) normalized for baseline infarct size. $\mathrm{MVO}^{\text {neg }}=$ patients without microvascular obstruction; MVO $^{\text {pos }}=$ patients with microvascular obstruction.

patients with MVO, mortality has been reported to increase by $75 \%$ at 1 month [18], $67 \%$ at 1 year [5] and $50 \%$ at 5 years [19]. In our study, MVO at day 5 was associated with LV remodelling at 6 months, as reflected by significantly increased left ventricular volumes assessed on MRI. These results are comparable to those of Orn et al. [7] at 1 year, and those of Nijveldt et al. [13] at 4 months, using the MRI technique.

This is strong evidence that both serial and singlepoint measurements of troponin correlate well with infarct size $[8,9,20]$. In routine practice, plasma levels of troponin I are used by the clinician to estimate the extent of necrosis. In our study, infarct size was significantly correlated with peak troponin and with the serial troponin I levels, except for troponin values at admission. To date, only 3 studies have investigated the relationship between MVO as assessed by MRI and serial troponin measurements, and the optimal timing for a single measurement. Our results confirm those of the literature. In the study of Neizel et al. [8], 61 patients with STEMI $<24 \mathrm{~h}$ reperfused by fibrinolysis or PCI, underwent MRI within $4 \pm 1$ days and serial troponin $\mathrm{T}$

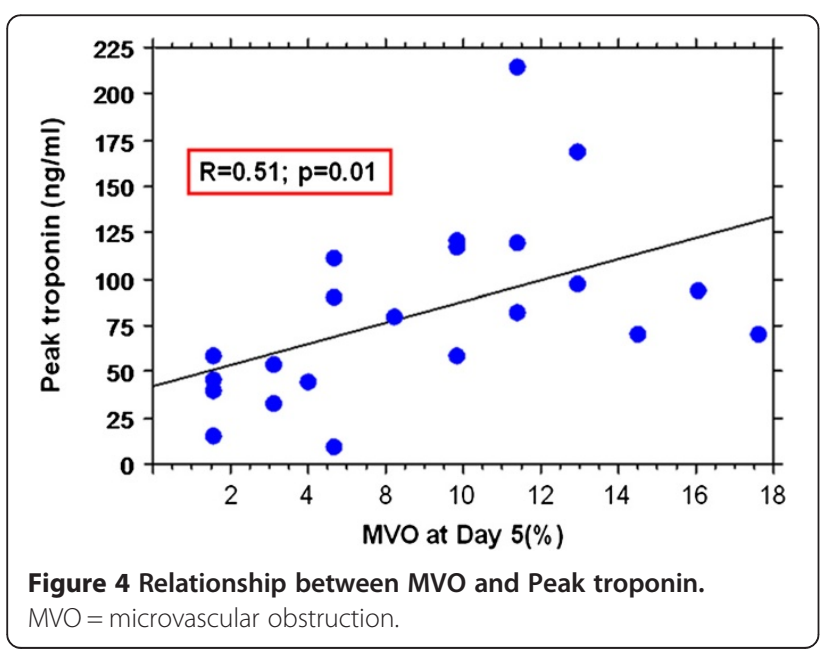

measurements at admission and after 24, 48, 72 and 96 hours. They found that a troponin $\mathrm{T}$ level $>2.52 \mu \mathrm{g} / \mathrm{l}$ at $24 \mathrm{~h}$ was a predictor for MVO with a sensitivity of $100 \%$ and a specificity of $80 \%$. In this study, Neizel et al. used troponin $\mathrm{T}$ levels, and no troponin measurements were performed between admission and $24 \mathrm{~h}$. Furthermore, MVO was evaluated on earlier delayed-enhancement imaging after contrast injection. Younger and al [9] enrolled 93 patients who underwent MRI on average $3.7 \pm$ 1.4 days after medical treatment for acute ST elevation or non-ST elevation myocardial infarction. Serum troponin I concentrations were sampled at $12 \mathrm{~h}$ and $72 \mathrm{~h}$ only after admission. They found a close relationship between a single measurement of troponin I at $72 \mathrm{~h}$ and the extent of MVO. The early and complete reperfusion of the infarct-related artery accelerates the appearance of cardiac enzymes in the first hours after reperfusion therapy. This wash-out phenomenon is characterized by a steeper rise and an earlier peak after successful restoration of anterograde coronary blood flow. These changes are more pronounced after mechanical reperfusion, which was used in our study, than after thrombolytic therapy [8]. Therefore, the almost exclusive reliance on thrombolytic therapy

Table 2 Correlation between the extent of MVO and troponin I levels

\begin{tabular}{lcc}
\hline & \multicolumn{2}{c}{ MVO (N = 29) } \\
\cline { 2 - 3 } & $\mathbf{r}$ & $\mathbf{p}$ \\
\hline Troponin peak & 0.51 & 0.01 \\
AUC troponin & 0.58 & 0.01 \\
Troponin on admission & 0.11 & 0.59 \\
Troponin at $6 \mathrm{H}$ & 0.57 & 0.01 \\
Troponin at $12 \mathrm{H}$ & 0.67 & $<0.0001$ \\
Troponin at $24 \mathrm{H}$ & 0.46 & 0.02 \\
Troponin at $48 \mathrm{H}$ & 0.57 & 0.01 \\
Troponin at $72 \mathrm{H}$ & 0.42 & 0.04 \\
\hline
\end{tabular}

$\mathrm{MVO}=$ microvascular obstruction; $\mathrm{AUC}=$ area under the curve; $\mathrm{H}=$ hours. 
Table 3 Cut-off value of cTnl predictive of MVO

\begin{tabular}{|c|c|c|c|c|c|}
\hline & Cut-off value (ng/ml) & Se (\%) & Sp (\%) & AUC ROC & $p$ \\
\hline Troponin at $\mathrm{H} 6$ & 44.6 & 74 & 65 & 0.729 & 0.0025 \\
\hline Troponin at $\mathrm{H} 12$ & 89 & 63 & 88 & 0.766 & 0.0002 \\
\hline Troponin at $\mathrm{H} 24$ & 27.4 & 65 & 81 & 0.703 & 0.0116 \\
\hline Troponin at $\mathrm{H} 48$ & 16.35 & 56 & 88 & 0.724 & 0.0041 \\
\hline Troponin at $\mathrm{H} 72$ & 7.9 & 71 & 65 & 0.68 & 0.0308 \\
\hline Peak troponin & 79.9 & 63 & 82 & 0.761 & 0.0003 \\
\hline AUC Troponin & 275.3 & 59 & 88 & 0.726 & 0.0057 \\
\hline
\end{tabular}

$\mathrm{Se}=$ sensitivity; $\mathrm{Sp}=$ specificity; $\mathrm{AUC}=$ area under the curve; $\mathrm{ROC}=$ receiver operating characteristic; $\mathrm{H}=$ hours.

in the study of Younger and al [9] may explain the more delayed troponin release observed. In study by Mayr and al [10], MRI was performed in 118 patients within 8 days after successful interventional reperfusion of STEMI. Cardiac troponin $\mathrm{T}$ concentrations were measured at least 3 times during the first $24 \mathrm{~h}$ after admission, and subsequently on days 1, 2, 3 and 4. These authors demonstrated that a peak troponin $>4.7 \mu \mathrm{g} / \mathrm{l}$ was predictive of $\mathrm{MVO}$ with a sensitivity of $78 \%$ and a specificity of $83 \%$.

One of the advantages of the present study is the large number of repeat troponin measures, at relatively short time intervals, which allowed more accurate determination of a threshold value that could predict MVO at the acute phase of infarction.

It has previously been shown that a longer duration of ischemia is associated with more pronounced impairment of myocardial perfusion and consequently, infarct size [30]. In our study, we observed a correlation between the extent of MVO and the time to reperfusion.

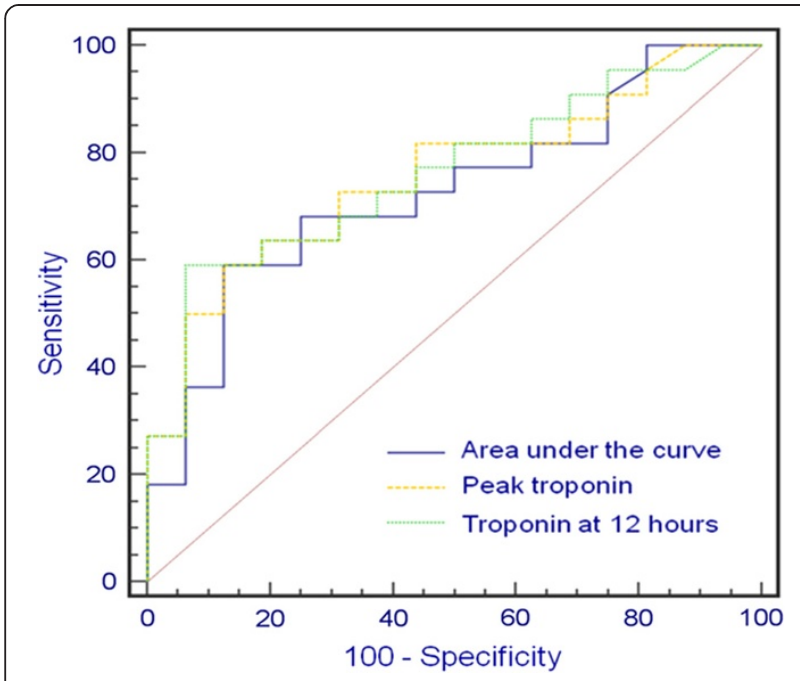

Figure 5 Cut-off value of cTnl predictive of MVO. ROC curves established for: AUC troponin ( $A \cup C_{\text {ROC }} 0.726,95 \%$ Cl 0.56-0.86). Peak troponin ( $A \cup C_{R O C} 0.757,95 \% \mathrm{Cl} 0.59-0.88$ ). Troponin at 12 hours (AUC $\left._{\mathrm{ROC}} 0.763,95 \% \mathrm{Cl} 0.6-0.88\right) \mathrm{CTnl}=$ cardiac troponin l; $\mathrm{MVO}=$ microvascular obstruction; $\mathrm{ROC}=$ receiver operating characteristic; $A \cup C=$ area under the curve.
Thus, the relation between troponin and the presence of MVO should be interpreted taking into account the time to reperfusion, since restoration of TIMI flow grade 3 by angioplasty does not necessarily guarantee the normalization of myocardial perfusion [31].

Newton et al. previously studied MVO on MRI in the context of non-ST elevation MI, and observed that MVO was correlated with infarct size and troponin levels. Thus, it would appear that the results observed in the context of STEMI are also applicable in NSTEMI [32].

\section{Study limitations}

This is a single-center study, with a relatively small population of highly selected patients. Nonetheless, the selection of the population made it possible to independently analyse MVO as evaluated by MRI in the absence of other cardiovascular comorbidities. Secondly, we did not evaluate blush grade, which corresponds to the angiographic evaluation of microcirculation after revascularisation. Our study focused on MVO at 5 days, which is a different phenomenon, and shown to be an independent prognostic factor in acute MI. These results merit further confirmation in a larger, prospective study. Thirdly, reperfusion strategy (primary PCI or thrombolysis) may possibly influence the occurrence of MVO. In particular, it has been shown that rescue PCI is associated with an increased thrombotic risk in this setting. However, in our study, only 6 (12\%) patients underwent rescue PCI. This likely did not impact on the relation observed between MVO and peak troponin, as there was no significant difference between groups (Table 1). Fourthly, MRI could not be performed in 6 patients $(11.7 \%)$ at 6 months. However, this does not impact the interpretation of the primary endpoint evaluated at 5 days.

\section{Conclusion}

Our results suggest a correlation between plasma levels of cardiac troponin I at the acute phase of AMI, and the extent of MVO as assessed by 3-T cardiac magnetic resonance imaging. The extent of MVO at 5 days post-STEMI is correlated with infarct size, and negatively impacts on 
LV remodeling at 6 months. A cut-off value of $89 \mathrm{ng} / \mathrm{mL}$ for $\mathrm{cTnI}$ at 12 hours seems to best predict the presence of early MVO with high sensitivity and specificity. Troponin measurement is an easily accessible prognostic marker that could help identify patients with MVO and unfavorable prognosis.

\section{Competing interests}

The authors declare that they have no competing interests.

\section{Authors' contributions}

Study conception and design: KP, MFS, NM. Acquisition of data: KP, RC, MFS, PP, FS, NM. Analysis and interpretation of data: FE, RC, PP, FS, NM. Drafting of the manuscript and critical revision: All. All authors read and approved the final version of the manuscript to be published. All authors agree to be accountable for all aspects of the work in ensuring that questions related to the accuracy or integrity of any part of the work are appropriately investigated and resolved.

Received: 2 January 2014 Accepted: 21 April 2014

Published: 30 April 2014

\section{References}

1. Van de Werf F, Bax J, Betriu A, Blomstrom-Lundqvist C, Crea F, Falk V, Filippatos G, Fox K, Huber K, Kastrati A, Rosengren A, Steg PG, Tubaro M, Verheugt F, Weidinger F, Weis M, ESC Committee for Practice Guidelines (CPG): Management of acute myocardial infarction in patients presenting with persistent ST-segment elevation: the task force on the management of ST-segment elevation acute myocardial infarction of the European society of cardiology. Eur Heart J 2008, 29:2909-2945.

2. Cochet AA, Lorgis L, Lalande A, Zeller M, Beer JC, Walker PM, Touzery C, Wolf JE, Brunotte F, Cottin Y: Major prognostic impact of persistent microvascular obstruction as assessed by contrast-enhanced cardiac magnetic resonance in reperfused acute myocardial infarction. Eur Radiol 2009, 19:2117-2126.

3. Hombach V, Grebe O, Merkle N, Waldenmaier S, Hoher M, Kochs M, Wohrle J, Kestler HA: Sequelae of acute myocardial infarction regarding cardiac structure and function and their prognostic significance as assessed by magnetic resonance imaging. Eur Heart J 2005, 26:549-557.

4. Wu KC, Zerhouni EA, Judd RM, Lugo-Olivieri CH, Barouch LA, Schulman SP, Blumenthal RS, Lima JA: Prognostic significance of microvascular obstruction by magnetic resonance imaging in patients with acute myocardial infarction. Circulation 1998, 97:765-772.

5. Ndrepepa G, Tiroch K, Keta D, Fusaro M, Seyfarth M, Pache J, Mehilli J, Schomig A, Kastrati A: Predictive factors and impact of no reflow after primary percutaneous coronary intervention in patients with acute myocardial infarction. Circ Cardiovasc Interv 2010, 3:27-33.

6. Bogaert J, Kalantzi M, Rademakers FE, Dymarkowski S, Janssens S: Determinants and impact of microvascular obstruction in successfully reperfused ST-segment elevation myocardial infarction: assessment by magnetic resonance imaging. Eur Radiol 2007, 17:2572-2580.

7. Orn S, Manhenke C, Greve OJ, Larsen Al, Bonarjee W, Edvardsen T, Dickstein K: Microvascular obstruction is a major determinant of infarct healing and subsequent left ventricular remodelling following primary percutaneous coronary intervention. Eur Heart J 2009, 30:1978-1985

8. Neizel M, Futterer S, Steen H, Giannitsis E, Reinhardt L, Lossnitzer D, Lehrke S, Jaffe AS, Katus HA: Predicting microvascular obstruction with cardiac troponin T after acute myocardial infarction: a correlative study with contrast-enhanced magnetic resonance imaging. Clin Res Cardiol 2009, 98:555-562.

9. Younger JF, Plein S, Barth J, Ridgway JP, Ball SG, Greenwood JP: Troponin-I concentration $72 \mathrm{~h}$ after myocardial infarction correlates with infarct size and presence of microvascular obstruction. Heart 2007, 93:1547-1551.

10. Mayr A, Klug G, Schocke M, Trieb T, Mair J, Pedarnig K, Pachinger O, Jaschke W, Metzler B: Late microvascular obstruction after acute myocardial infarction: relation with cardiac and inflammatory markers. Int J Cardiol 2012, 157:391-396.

11. Bekkers SC, Smulders MW, Passos VL, Leiner T, Waltenberger J, Gorgels AP, Schalla S: Clinical implications of microvascular obstruction and intramyocardial haemorrhage in acute myocardial infarction using cardiovascular magnetic resonance imaging. Eur Radiol 2010, 20:2572-2578.

12. Morishima I, Sone T, Okumura K, Tsuboi H, Kondo J, Mukawa H, Matsui H, Toki Y, Ito T, Hayakawa T: Angiographic no-reflow phenomenon as a predictor of adverse long-term outcome in patients treated with percutaneous transluminal coronary angioplasty for first acute myocardial infarction. J Am Coll Cardiol 2000, 36:1202-1209.

13. Nijveldt R, Hofman MB, Hirsch A, Beek AM, Umans VA, Algra PR, Piek JJ, van Rossum AC: Assessment of microvascular obstruction and prediction of short-term remodeling after acute myocardial infarction: cardiac MR imaging study. Radiology 2009, 250:363-370.

14. Bolognese L, Carrabba N, Parodi G, Santoro GM, Buonamici P, Cerisano G, Antoniucci D: Impact of microvascular dysfunction on left ventricular remodeling and long-term clinical outcome after primary coronary angioplasty for acute myocardial infarction. Circulation 2004, 109:1121-1126.

15. Larose E, Rodes-Cabau J, Pibarot P, Rinfret S, Proulx G, Nguyen CM, Dery JP, Gleeton O, Roy L, Noel B, Barbeau G, Rouleau J, Boudreault JR, Amyot M, De Larochellière R, Bertrand OF: Predicting late myocardial recovery and outcomes in the early hours of ST-segment elevation myocardial infarction traditional measures compared with microvascular obstruction, salvaged myocardium, and necrosis characteristics by cardiovascular magnetic resonance. J Am Coll Cardiol 2010, 55:2459-2469.

16. Tarantini G, Razzolini R, Cacciavillani L, Bilato C, Sarais C, Corbetti F, Marra MP, Napodano M, Ramondo A, liceto S: Influence of transmurality, infarct size, and severe microvascular obstruction on left ventricular remodeling and function after primary coronary angioplasty. Am J Cardiol 2006, 98:1033-1040.

17. Gerber BL, Rochitte CE, Melin JA, McVeigh ER, Bluemke DA, Wu KC, Becker LC, Lima JA: Microvascular obstruction and left ventricular remodeling early after acute myocardial infarction. Circulation 2000, 101:2734-2741.

18. Brosh D, Assali AR, Mager A, Porter A, Hasdai D, Teplitsky I, Rechavia E, Fuchs S, Battler A, Kornowski R: Effect of no-reflow during primary percutaneous coronary intervention for acute myocardial infarction on six-month mortality. Am J Cardiol 2007, 99:442-445.

19. Ndrepepa G, Tiroch K, Fusaro M, Keta D, Seyfarth M, Byrne RA, Pache J, Alger P, Mehilli J, Schomig A, Kastrati A: 5-year prognostic value of no-reflow phenomenon after percutaneous coronary intervention in patients with acute myocardial infarction. J Am Coll Cardiol 2010, 55:2383-2389

20. Giannitsis E, Steen H, Kurz K, Ivandic B, Simon AC, Futterer S, Schild C, Isfort P, Jaffe AS, Katus HA: Cardiac magnetic resonance imaging study for quantification of infarct size comparing directly serial versus single time-point measurements of cardiac troponin T. J Am Coll Cardiol 2008, 51:307-314

21. Bassand JP, Hamm CW, Ardissino D, Boersma E, Budaj A, Fernandez-Aviles F, Fox KA, Hasdai D, Ohman EM, Wallentin L, Wijns W: Guidelines for the diagnosis and treatment of non-ST-segment elevation acute coronary syndromes. Eur Heart J 2007, 28:1598-1660.

22. Thygesen K, Alpert JS, White HD, Jaffe AS, Apple FS, Galvani M, Katus HA, Newby LK, Ravkilde J, Chaitman B, Clemmensen PM, Dellborg M, Hod H, Porela P, Underwood R, Bax JJ, Beller GA, Bonow R, Van der Wall EE, Bassand JP, Wijns W, Ferguson TB, Steg PG, Uretsky BF, Williams DO, Armstrong PW, Antman EM, Fox KA, Hamm CW, Ohman EM, et al: Universal definition of myocardial infarction. Circulation 2007, 116:2634-2653.

23. The thrombolysis in myocardial infarction (TIMI) trial: phase I findings: TIMI study group. N Engl J Med 1985, 312:932-936.

24. Kim HW, Farzaneh-Far A, Kim RJ: Cardiovascular magnetic resonance in patients with myocardial infarction: current and emerging applications. J Am Coll Cardiol 2009, 55:1-16.

25. Kloner RA, Ganote CE, Jennings RB: The "no-reflow" phenomenon after temporary coronary occlusion in the dog. J Clin Invest 1974, 54:1496-1508

26. Eeckhout E, Kern MJ: The coronary no-reflow phenomenon: a review of mechanisms and therapies. Eur Heart J 2001, 22:729-739.

27. Bekkers SC, Yazdani SK, Virmani R, Waltenberger J: Microvascular obstruction: underlying pathophysiology and clinical diagnosis. J Am Coll Cardiol 2010, 55:1649-1660.

28. Lima JA, Judd RM, Bazille A, Schulman SP, Atalar E, Zerhouni EA: Regional heterogeneity of human myocardial infarcts demonstrated by contrast-enhanced MRI: potential mechanisms. Circulation 1995, 92:1117-1125. 
29. Robbers LF, Eerenberg ES, Teunissen PF, Jansen MF, Hollander MR, Horrevoets AJ, Knaapen P, Nijveldt R, Heymans MW, Levi MM, van Rossum AC, Niessen HW, Marcu CB, Beek AM, van Royen N: Magnetic resonance imaging-defined areas of microvascular obstruction after acute myocardial infarction represent microvascular destruction and haemorrhage. Eur Heart J 2013, 34:2346-2353.

30. Tarantini G, Cacciavillani L, Corbetti F, Ramondo A, Marra MP, Bacchiega E, Napodano M, Bilato C, Razzolini R, lliceto S: Duration of ischemia is a major determinant of transmurality and severe microvascular obstruction after primary angioplasty: a study performed with contrast-enhanced magnetic resonance. J Am Coll Cardiol 2005, 46:1229-1235.

31. De Luca G, Hof AW v't, de Boer MJ, Ottervanger JP, Hoorntje JC, Gosselink AT, Dambrink JH, Zijlstra F, Suryapranata H: Time-to-treatment significantly affects the extent of ST-segment resolution and myocardial blush in patients with acute myocardial infarction treated by primary angioplasty. Eur Heart J 2004, 25:1009-1013.

32. Mewton N, Bonnefoy E, Revel D, Ovize M, Kirkorian G, Croisille P: Presence and extent of cardiac magnetic resonance microvascular obstruction in reperfused non-ST-elevated myocardial infarction and correlation with infarct size and myocardial enzyme release. Cardiology 2009, 113:50-58.

doi:10.1186/1471-2261-14-57

Cite this article as: Pernet et al: Microvascular obstruction assessed by 3-tesla magnetic resonance imaging in acute myocardial infarction is correlated with plasma troponin I levels. BMC Cardiovascular Disorders 2014 14:57.

\section{Submit your next manuscript to BioMed Central and take full advantage of:}

- Convenient online submission

- Thorough peer review

- No space constraints or color figure charges

- Immediate publication on acceptance

- Inclusion in PubMed, CAS, Scopus and Google Scholar

- Research which is freely available for redistribution 